УДК 621.314

\title{
О ЗАЩИТЕ СИЛОВЫХ МОДУЛЕЙ МНОГОУРОВНЕВЫХ ПРЕОБРАЗОВАТЕЛЕЙ ЧАСТОТЫ
}

\author{
КУЛИК М. В., РЯЗАНЦЕВ О. В.
}

\author{
Днепродзержинский государственный технический университет, \\ Украина, Днепродзержинск, 51900, Днепростроевская 2
}

\begin{abstract}
Аннотация. В статье предложено решение проблемы, связаной с согласованием уровней и формы импульсов, генерируемых микроконтроллером, с сигналами управления входами силовых транзисторов. Она возникает при разработке преобразователей энергии с использованием широтно-импульсной модуляции. Также в работе проанализированы различные существующие методы защиты силовых модулей с целью максимально эффективного использования их мощностных характеристик
\end{abstract}

Ключевые слова: силовой модуль; преобразователь энергии; система управления; широтно-импульсная модуляция; IGBT-транзистор; MOSFET-транзистор; схема Дарлингтона; асинхронный двигатель; микроконтроллер

\section{ВВЕДЕНИЕ}

Замена существующих аналоговых систем управления с тиристорными силовыми элементами на полностью цифровые системы привела к созданию преобразователей частоты с микроконтроллерным управлением, что позволяет оптимизировать энергозатраты при любом заданном режиме работы [1]. Однако существующие системы управления недостаточно надежны и имеют высокую себестоимость. В связи с этим данная работа посвящена устранению указанных недостатков, в частности: оптимизации сигналов управления по форме и размаху, защите силовых модулей в экстремальных режимах работы.

Особое внимание посвящено вопросу помехоустойчивости, что обеспечивает надежную работу устройства при наличии внешних электромагнитных воздействий различной природы. Также в работе проанализированы различные существующие методы защиты си- ловых модулей с целью максимально эффективного использования их мощностных характеристик. Проведен анализ эффективности согласования системы защиты для различных типов силовых модулей с микроконтроллерной системой управления, решалась задача оптимального управления силовыми модулями в экстремальных режимах работы преобразователя частоты.

В простейшем варианте цифрового представления синусоиды используется однопозиционный код, которому соответствует 2 уровня квантования. Такое представление синусоиды является достаточно грубым, но обеспечивает максимальную простоту системы защиты. Если число уровней квантования больше двух, построение системы защиты существенно усложняется. В статье разработан и исследован комбинированный многоуровневый вариант системы защиты. 